\title{
Constraints on radon and SGD temporal variability in a semiarid, well-mixed estuary
}

\author{
WILliam W. WOLFE ${ }^{1}$, DORINA MURGULET ${ }^{2}$ \\ ${ }^{1,2}$ Center for Water Supply Studies, Texas A\&M University \\ Corpus Christi \\ 1 (wwolfe1@islander.tamucc.edu) \\ 2 (dorina.murgulet@tamucc.edu)
}

Submarine groundwater discharge (SGD) is defined as any and all types of water flow from the seabed to the coastal ocean, which includes both terrestrial/groundwater and oceanic/recirculated components. Although diffuse, and difficult to measure, SGD represents a significant source of freshwater and solutes to near-shore marine environments. Because radioisotopes like ${ }^{222} \mathrm{Rn}\left(\mathrm{t}_{1 / 2}=3.82\right.$ days) and it's parent, ${ }^{226} \mathrm{Ra}\left(\mathrm{t}_{1 / 2} 1600 \mathrm{yrs}\right)$, are more concentrated in groundwater than surface waters, they are ideal tracers of SGD in marine environments. Here we measure surface water variability of tracer activity in response to atmospheric and hydrologic factors over an extended time period with high frequency. ${ }^{222} \mathrm{Rn}$ is measured nearly continuously at a near-shore platform every 30 minutes, and ${ }^{226} \mathrm{Ra}$ is measured 1-3 times per week at the same site. The study will last more than 14 months, and the number of measurements is expected to reach 20,000 upon completion. Hydroparameters at the study site, including wind speed, wind direction, groundwater and tide level, temperature, salinity and precipitation are recorded and compared to tracer measurements using various statistical analyses. The preliminary correlations we observe expose trends that would otherwise be obscured over shorter study periods or longer intervals. Wind direction and speed seem to be largely responsible for the observed variability. We integrate the impact of environmental factors on groundwater tracer variability into SGD mass-balance equations, leading to an improved model for seepage rate estimation.

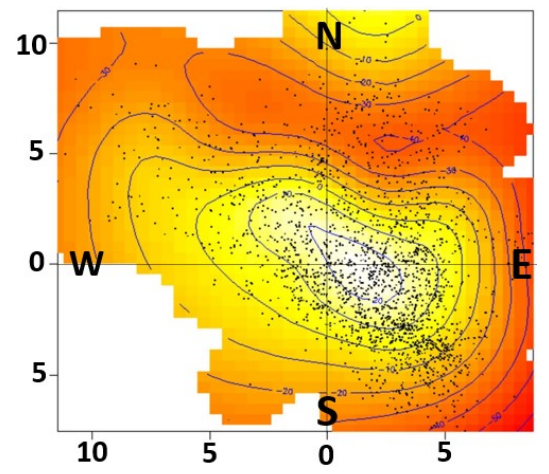

Figure: generalized additive model showing wind speed vector $(\mathrm{m}$ $\left.\mathrm{s}^{-1}\right)$ as black dots and associated ${ }^{222} \mathrm{Rn}$ activity (white is greater). 